\section{Research Square}

Preprints are preliminary reports that have not undergone peer review.

They should not be considered conclusive, used to inform clinical practice, or referenced by the media as validated information.

\title{
Evolution of codon usage in 2019-new coronavirus causing human infection
}

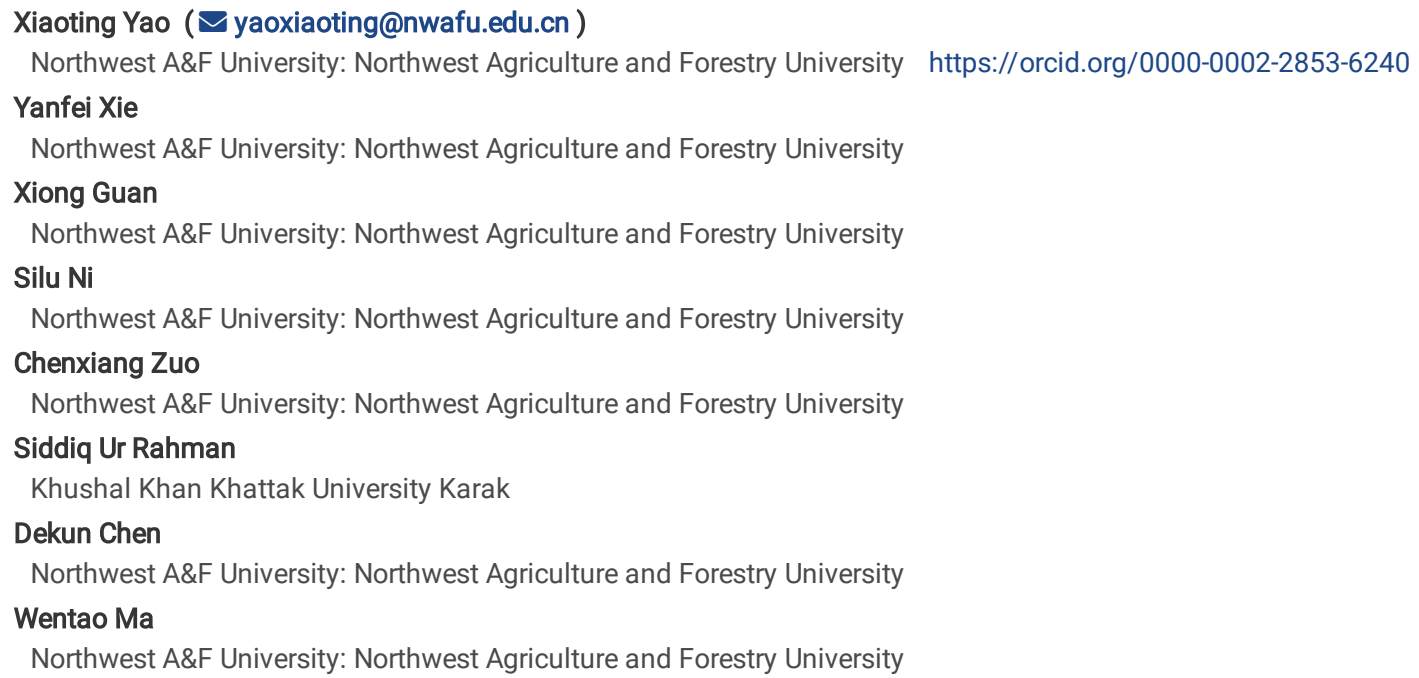

Research

Keywords: SARS-Cov-2, coronavirus, nucleotide composition, codon usage bias, evolution

Posted Date: September 10th, 2020

DOI: https://doi.org/10.21203/rs.3.rs-70887/v1

License: (c) (1) This work is licensed under a Creative Commons Attribution 4.0 International License. Read Full License 


\section{Abstract}

Background: The recent emergence of viral pneumonia was caused by the novel coronavirus (SARS-Cov-2), which has spread to many countries and threated the global public health.

Results: In the current study, we provide a primary evolutionary analysis based on the codon usage patterns of SARS-Cov-2 genome sequences. We employed bioinformatics technologies to measure the nucleotide compositions, the relative synonymous codon usage (RSCU), the codon adaptation index (CAI), and other indices. Our results reflected that there were some similarities of codon usage bias between SARS-Cov-2 and its natural reservoirs, suggesting that SARSCov-2 was tended to evolve its codon usage which was comparable to that of its hosts. Additionally, various degree of adaptation to the SARS-Cov-2 host and vector were estimated, even different genes have different codon adaptation to their reservoirs. We further suggested that SARS-Cov-2 isolates were evolving at a rapid substitution rate under their translation selection pressure of their hosts.

Conclusions: The findings of the present study will provide help for the understanding of the elements leading to viral evolution and adaptation to reservoirs.

\section{Background}

SARS-Cov-2, a novel coronavirus, has brought unprecedented panic to people throughout the world since the December of 2019 [1-4]. The SARS-Cov-2 outbreak was a Public Health Emergency of International Concern (PHEIC) that has become a global pandemic [1]. Until now, the virus is spreading in various countries and the healthcare systems in many countries strive. Some reports suggested that SARS-Cov-2 was a relative of the severe acute respiratory syndrome (SARS), which was characterized by the flu-like symptoms such as fever, cough and may transmit from animals to humans [3, 5]. The SARS was initially traced to palm civets while was later determined as the bats [6, 7]. Recent study has demonstrated that bats or snakes were the potential natural hosts of SARS-Cov-2 [8]. However, on the basis of the recent researches, the origin of SARS-Cov-2 is still unclear.

The coronavirinae family contains four genera according to their hereditary properties, such as Alphacoronavirus, Betacoronavirus, Gammacoronavirus and Deltacoronavirus [5]. The coronavirus RNA genome is the largest one among all RNA viruses, and ranges from 26 to $32 \mathrm{~kb}$ [9]. Some studies have shown that the SARS-Cov-2 belongs to betacoronaviruses on the basis of sequence analysis, which also includes SARS-CoV, the Middle East respiratory syndrome coronavirus (MERS-CoV), Bat-SARS-like (SL) -ZC45 and Bat-SL ZXC21. According to the phylogenetic analysis, SARS-Cov-2 is more closely with bat-SL-CoV ZC45 and bat-SL-CoV ZXC2, while is more distantly with SARS-CoV [5]. This new CoV can infect the lower respiratory tract in humans, but it shows apparently that the symptoms of SARS-Cov-2 are milder than that of SARS and MERS $[5,9]$. The virus has a nucleocapsid consisted of genomic RNA and four major structural genes, which encode the spike glycoprotein (S), the membrane protein (M), the envelope protein (E) and the phosphorylated nucleocapsid protein $(\mathrm{N})$. N protein is embedded in lipid bilayers and covered with various types of S proteins, including the spike glycoprotein trimmer and the hemagglutininesterase (HE). Besides, $M$ proteins and $E$ proteins are found to locate among $S$ proteins in the viral envelope [9].

Synonymous codon usage patterns have been widely reported in organisms, especially in viruses [10-13]. In general, 61 codons can encode 20 different amino acids, so most of them are synonymous codons. Many studies have suggested that each codon was applied in different rates within different individuals and even within various genes of one genome [14-21]. This phenomenon was regarded as codon usage bias. Many researches demonstrated that several factors can force codon usage patterns, such as mutational pressure, protein translation, replication and transcriptional factors [22-24]. However, natural selection pressure and compositional constraint are considered as the dominant roles that may cause the variation of codon usage patterns among various organisms $[10,25]$.

At present, there is no evidence indicating a clear host to be SARS-Cov-2 reservoir. Studies of codon usage patterns between virus and its reservoirs showed viruses tended to evolve their codon usage patterns that were parallel to its reservoirs [26, 27]. To investigate the potential virus reservoirs and their influences on viral codon usage patterns, we have implemented a comprehensive analysis and comparison. Our results suggest the codon usage patterns of bat are more close to that of SARS-Cov-2, and the viral codon usage patterns are mainly shaped by the translational selection. More interestingly, we explored the adaptation of SARS-Cov-2 to its reservoirs and found the different genes have different adaptation to their hosts, which may explain their different efficiency of protein synthesis within their hosts. We also identified that SARS-Cov-2 isolates were evolving at a rapid substitution rate under their translation selection pressure of their hosts.

\section{Results}

\section{Phylogenetic classification}

Phylogenetic analysis of 41 SARS-Cov-2 whole genomes indicated that all SARS-Cov-2 strains were clustered into separate clades (Fig. 1). In the tree, SARSCov-2 of China (Wuhan) formed a distinct clade, and most of SARS-Cov-2 of USA clustered together in another clade. SARS-Cov-2 of China (Yunnan and Shenzhen), Australia and South Korea were more closely related to that of USA, and the virus of China (Hangzhou) was more closely related to that of China (Wuhan). Besides, SARS-Cov-2 of Japan were distributed in different clades.

\section{A/U nucleotides are more frequent than G/C in SARS-Cov-2 coding sequences}

We analyzed 41 whole genomes of SARS-Cov-2, which originates from humans infected in different countries during 2019 to 2020 . Our results suggested that the four nucleotides were used at unequal frequencies, the genome compositions were significantly enriched for AU (62.00\% \pm 0.02$)$ over GC ( $38.00 \% \pm 0.01)$ 
(Table 1, Fig. S1 (A), wilcox.test, $\mathrm{P}<0.01)$. Additionally, the mean count of nucleotides A $(29.90 \% \pm 0.03)$ and $\mathrm{U}(32.11 \% \pm 0.01)$ were significantly higher than $\mathrm{G}(19.62 \% \pm 0.01)$ and C $(18.38 \% \pm 0.01)$ (Table 1, Fig. S1 (C), wilcox.test, $\mathrm{P}<0.01)$. These results were consistent with our prior study of Crimean-Congo hemorrhagic fever virus, which was also indicated the frequencies of $A$ and $U$ were higher than that of $C$ and $G$ [17] 
Table 1

Nucleotide composition analysis of SARS-Cov-2 complete sequences (\%).

\begin{tabular}{|c|c|c|c|c|c|c|c|c|c|c|c|c|c|c|c|}
\hline Accession ID & A & U & G & C & $A U$ & GC & A3 & U3 & G3 & C3 & AU3 & GC3 & GC1 & GC2 & GC12 \\
\hline No & .89 & 1 & 2 & 8 & 0 & 0 & 8 & 4 & 3 & 7 & 0 & 0 & 90 & 4.10 & 9.50 \\
\hline$\Lambda$ & 9.89 & & & 8.38 & & & 8.18 & & & 19.87 & & 0 & & 0 & 9.50 \\
\hline LC522 & 2000 & 1 & 2 & 18.37 & & & 1 & & 0 & 26.80 & & & & 4.10 & 9.50 \\
\hline LC522 & 9.89 & 211 & 9.62 & & & & 9.60 & 3.07 & 7.77 & 26.80 & & 90 & & 4.10 & 9.50 \\
\hline LC52 & 9.89 & 11 & 19.62 & 18.37 & .00 & 99 & 39.60 & & 17.77 & 8 & & 0 & & 0 & 9.50 \\
\hline LC522972.1 & 29.89 & 32.11 & 19.62 & 18.37 & 62.00 & 37.99 & 39.60 & 4 & 17.79 & 26.78 & 6 & 0 & & .10 & 29.50 \\
\hline MT039888.1 & 29.89 & 32.12 & 19.62 & 1837 & 62.01 & 9 & 3 & 4 & 79 & 2 & 0 & 0 & & 0 & 9.50 \\
\hline LC52 & 9.88 & 32.13 & 19.61 & 18.38 & 6 & 9 & 39.5 & 4 & 17.82 & 1 & 6 & 0 & 0 & 4.10 & 29.50 \\
\hline МT020881.1 & 29.89 & 32.1 & 19.62 & 18.38 & 6 & 38.00 & 39.59 & 9 & 17.79 & 8 & 6 & 0 & 0 & 4.10 & 29.50 \\
\hline МТ020880.1 & 9.89 & 32.1 & 19.62 & 18.38 & 62.00 & 38.00 & 39.59 & 09 & 17.79 & 8 & 6 & 90 & & 4.10 & 29.50 \\
\hline MN985325.1 & 29.89 & 3 & 1 & 18.38 & 6 & 3 & 3 & & 17.79 & 8 & 65 & 90 & & 1.10 & 29.50 \\
\hline MT044258.1 & 29.90 & 32.10 & 19.62 & 18.39 & 62.00 & 38.01 & 39.60 & 43.05 & 17.80 & 26.79 & 65.00 & 35.00 & 90 & 0 & 29.50 \\
\hline MT044 & مه 20 & 32.1 & 19.62 & 1838 & 6 & 3 & 39 & 4 & 17 & 2 & 0 & 0 & 70 & 0 & 8.90 \\
\hline МТ039887.1 & 29.89 & 32.1 & 19.62 & 18.38 & 62.00 & 38.00 & (3).00 & 43.09 & 17.79 & 26.78 & 65.10 & & & 24.10 & 29.50 \\
\hline MT027064.1 & 29.89 & 32.11 & 19.62 & 18.37 & 02.00 & 37.99 & 39.59 & 43.09 & 11.19 & 26.78 & 65.10 & 34.90 & 4.90 & 24.10 & 29.50 \\
\hline MT027063.1 & 29.89 & 32.11 & 19.62 & 18.38 & 62.00 & 38.00 & 39.59 & 43.09 & 17.79 & & & 90 & & 0 & 29.50 \\
\hline MT0 & 29.89 & 32.11 & 19.62 & 18.38 & 62.00 & 38.00 & 39.59 & & 17.79 & & & & & 0 & 29.50 \\
\hline MN997409.1 & 29.89 & 32.11 & 19.62 & 18.38 & 62.00 & 38.00 & 39.60 & 43.08 & 17.77 & 26.79 & 65 & 34.90 & 90 & 0 & 29.50 \\
\hline MN994468.1 & 29.90 & 32.11 & 19.62 & 18.37 & 62.01 & 99 & 39.60 & 43.07 & 17.79 & 26.79 & 65.10 & 34.90 & 34.90 & 0 & 29.50 \\
\hline MN994467.1 & 2000 & 2211 & 1061 & 1020 & 62.00 & חת 20 & 70 & 43.08 & 1770 & 26.81 & 65.00 & 35.00 & 90 & 4.10 & 29.50 \\
\hline MN988713.1 & 29.89 & 32.10 & 19.62 & 18.37 & 61.9 & 37.99 & 39.59 & 43. & 17.77 & 26.76 & . & 34.90 & 34.10 & 24.40 & 29.25 \\
\hline MN975262.1 & 29.92 & 32.10 & 19.61 & 10.01 & 02.02 & 31.98 & 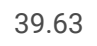 & & ט.17 & 26.78 & & & & .10 & 29.50 \\
\hline MN938384.1 & 29.86 & 32.13 & 19.64 & 18.38 & 61.99 & 38.02 & 38.56 & & 29.98 & 23.92 & & & & 24.10 & 29.50 \\
\hline МT007544.1 & 29.95 & 32.08 & 19.60 & 18.37 & 62.03 & 37.97 & 39.79 & 43.01 & 17.73 & 26.79 & 65.10 & 34.90 & & 24.10 & 29.50 \\
\hline МT039873.1 & 29.87 & 2211 & 19.63 & 18.39 & 98 & 38 ר 38 & ב5 & 4 & 17.80 & 1 & 65.00 & .00 & & & 29.50 \\
\hline MTO & an & 32.11 & 19.62 & 30 & 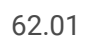 & 3 & 39.60 & 4 & 7 & 2 & 0 & 0 & 0 & 0 & .50 \\
\hline МT019532.1 & 29.91 & Sर. & 19.62 & 18.37 & & $3 \pi$ & . & & & & & 0 & & 0 & 29.50 \\
\hline МT019531.1 & 29.93 & 32.00 & 19.61 & 10.01 & 62.01 & & (5).0 & 43.06 & 11.18 & 26.80 & & 34.90 & & & 29.50 \\
\hline MT019530.1 & 29.92 & 32.09 & 19.62 & 18.38 & 62.01 & 38.00 & no & 43.05 & 17.79 & 26.82 & 65.00 & 35.00 & & & 29.50 \\
\hline МT019529.1 & 29.93 & 32.08 & 19.62 & 18.37 & 62.01 & 37.99 & 39.64 & 43.07 & 17.79 & 26.79 & 65.10 & 34.90 & 34.90 & 24.10 & 29.50 \\
\hline MT066176.1 & 29.86 & 32.12 & 19.63 & 18.38 & 61.98 & 38.01 & 9.55 & 43.08 & 17.80 & 26.79 & 65.00 & 35.00 & 34.90 & 24.10 & 29.50 \\
\hline МТ066175.1 & 29.87 & 32.12 & 19.63 & 18.39 & 61.99 & 38.02 & 39.55 & 43.08 & 17.80 & 26.79 & 65.00 & 35.00 & 34.90 & 24.10 & 29.50 \\
\hline МT049951.1 & 29.95 & 32.08 & 19.60 & 18.37 & 62.03 & 37.97 & 39.67 & 43.09 & 17.76 & 26.78 & 65.10 & 34.90 & 34.90 & 24.10 & 29.50 \\
\hline MT039890.1 & 29.95 & 32.10 & 19.00 & 18.36 & 5 & 6 & 39.67 & 4 & $y$ & 9 & 0 & 90 & 30 & 90 & 28.90 \\
\hline MN996531.1 & 29.86 & 32.12 & 19.63 & 18.39 & 61.98 & 38.02 & 30 & 4 & 21.34 & 88 & 68.10 & 31.90 & 90 & 10 & 29.50 \\
\hline MN996530.1 & 29.86 & 32.12 & 19.63 & 18.39 & 61.98 & 38.02 & 38.56 & 33.94 & 29.98 & 23.92 & 58.60 & 41.40 & 34.90 & 24.10 & 29.50 \\
\hline MN996529.1 & 29.86 & 32.12 & 19.63 & 18.39 & 61.98 & 38.02 & 39.53 & 43.08 & 17.81 & 26.81 & 65.00 & 35.00 & 34.90 & 24.10 & 29.50 \\
\hline
\end{tabular}

ENC represents the effective number of codons.

$\mathrm{GC12}$ represents the $\mathrm{G}+\mathrm{C}$ content at the first and second positions of codons.

GC3 represents the $\mathrm{G}+\mathrm{C}$ content at the third positions of codons.

AU3 represents the $A+U$ content at the third positions of codons. 


\begin{tabular}{|c|c|c|c|c|c|c|c|c|c|c|c|c|c|c|c|}
\hline Accession ID & A & $\mathrm{U}$ & G & C & $A U$ & GC & A3 & U3 & G3 & C3 & AU3 & GC3 & GC1 & GC2 & GC12 \\
\hline MN996528.1 & 29.92 & 32.10 & 19.61 & 18.37 & 62.02 & 37.98 & 39.62 & 43.07 & 17.78 & 26.79 & 65.10 & 34.90 & 34.90 & 24.10 & 29.50 \\
\hline MN996527.1 & 29.85 & 32.13 & 19.63 & 18.38 & 61.98 & 38.01 & 39.56 & 43.09 & 17.80 & 26.79 & 65.00 & 35.00 & 34.90 & 24.10 & 29.50 \\
\hline MN908947.3 & 29.94 & 32.08 & 19.61 & 18.37 & 62.02 & 37.98 & 39.66 & 43.07 & 17.77 & 26.79 & 65.10 & 34.90 & 34.90 & 24.10 & 29.50 \\
\hline NC_045512.2 & 29.94 & 32.08 & 19.61 & 18.37 & 62.02 & 37.98 & 39.66 & 43.07 & 17.77 & 26.79 & 65.10 & 34.90 & 34.90 & 24.10 & 29.50 \\
\hline $\begin{array}{l}\text { Mean } \\
\pm \text { SD }\end{array}$ & $\begin{array}{l}29.90 \\
\pm 0.03\end{array}$ & $\begin{array}{l}32.11 \\
\pm 0.01\end{array}$ & $\begin{array}{l}19.62 \\
\pm 0.01\end{array}$ & $\begin{array}{l}18.38 \\
\pm 0.01\end{array}$ & $\begin{array}{l}62.00 \\
\pm 0.02\end{array}$ & $\begin{array}{l}38.00 \\
\pm 0.01\end{array}$ & $\begin{array}{l}39.45 \\
\pm 0.43\end{array}$ & $\begin{array}{l}42.83 \\
\pm 2.16\end{array}$ & $\begin{array}{l}18.64 \\
\pm 2.76\end{array}$ & $\begin{array}{l}26.14 \\
\pm 1.89\end{array}$ & $\begin{array}{l}64.98 \\
\pm 1.67\end{array}$ & $\begin{array}{l}35.02 \\
\pm 1.67\end{array}$ & $\begin{array}{l}34.85 \\
\pm 0.22\end{array}$ & $\begin{array}{l}24.08 \\
\pm 0.19\end{array}$ & $\begin{array}{l}29.46 \\
\pm 0.14\end{array}$ \\
\hline
\end{tabular}

ENC represents the effective number of codons.

$\mathrm{GC1} 2$ represents the $\mathrm{G}+\mathrm{C}$ content at the first and second positions of codons.

GC3 represents the $\mathrm{G}+\mathrm{C}$ content at the third positions of codons.

AU3 represents the $A+U$ content at the third positions of codons.

To investigate the magnitude of codon usage bias in SARS-Cov-2, we calculated the mean values of nucleotide contents for all triplets during the research. At the third codon position, the nucleotide percentage of A3 (39.45\% \pm 0.43$)$ and U3 (42.83\% \pm 2.16$)$ were significantly higher than G3 (18.64\% \pm 2.76$)$ and C3 $(26.14 \% \pm 1.89)$ (Table 1, Fig. S1 (D), wilcox.test, $P<0.01)$. These values were similar with the total nucleotide composition, showing that $A 3, \mathrm{U} 3$, G3 and $C 3$ may be influenced by the total nucleotide composition. GC nucleotide composition at each codon position was also considered to reflect the base composition bias. The ranges of GC content were as follows: $33.70-34.90 \%$ (mean $=34.85, \mathrm{SD}=0.22)$ at the first codon position; $22.90-24.40 \%(\mathrm{mean}=24.08, \mathrm{SD}=0.19)$ at the second codon position; and $28.90-29.50 \%$ (mean $=29.46, S D=0.14$ ) at the first and second codon positions. In addition, the mean values of AU3 and GC3 compositions were $64.98 \% \pm 1.67$ and $35.02 \% \pm 1.67$, respectively, suggesting that $A$ and $U$ nucleotides may be more enriched in the end of codons (Table 1, Fig. S1 (B), wilcox.test, $\mathrm{P}<0.01$ ).

\section{Codon usage patterns of SARS-Cov-2 and its hosts}

The RSCU analysis was used to estimate the codon usage patterns of SARS-Cov-2 complete genomes and their major gene sequences. Among the eighteen most abundantly used codons in SARS-Cov-2 complete genomes, twelve codons [UUU (Phe), UUA (Leu), AUU (Ile), GUU (Val), AGU (Ser), CCU (Pro), ACA (Thr), GCU (Ala), UAU (Tyr), UGU (Cys), AGA (Arg) and GGU (Gly)] had A/U at the end (three A-ended; nine U-ended) and the remaining six [CAC (His), CAG (Gln), AAC (Asn), AAG (Lys) and GAC (Asp)] had G/C at the end (three C-ended; three G-ended), when the SARS-Cov-2 coding sequences were similar according to their gene groups. This indicates that A- and U-ended codons are preferred in the SARS-Cov- 2 coding sequences. An analysis of overall RSCU values showed that 3 of the 18 preferred codons [ACA (Thr), AGA (Trg) and GGU (Gly)] had RSCU values > 1.6, while RSCU values for the remaining preferred codons were >0.6 and $<1.6$. The evaluation of overall RSCU values may potentially hide gene-specific patterns, thus we also estimated the RSCU values of SARS-Cov-2 coding sequences based on the gene groups. We found that the preferred codons were differentiated among the gene groups. The ratios of consistent/inconsistent preferred codons between the SARS-Cov-2: E gene, M gene, $2 \mathrm{~N}$ gene and S gene were 4:14, 6:12, 4:14 and 8:10, respectively (Table 2, Fig. S2). Patterns of gene-specific over-represented codons were also observed in the SARS-Cov-2 isolates, 11 of the 18 preferred codons were over-represented in the E gene, 10 of the 18 were over-represented in the $\mathrm{M}$ gene, 6 of 18 were over-represented in the $\mathrm{N}$ gene and 9 of 18 were over-represented in the $\mathrm{S}$ gene. The gene-specific RSCU patterns indicated the independent evolution dynamics of the SARS-Cov-2 isolates. In addition, to estimate the potential effects of the host and vector on the viral codon usage pattern, the RSCU patterns were considered and matched with various potential hosts such as human and bat (Table 2, Fig. S2). Among these 18 preferred codons, we found that the ratio of common/uncommon preferred codons was 6:12 between SARS-Cov-2 and human and 13:5 between SARS-Cov-2 and bat (Table 2, Fig. S2). 
Table 2

The relative synonymous codon usage frequency (RSCU) of SARS-Cov-2 complete genomes, major viral genes, its natural hosts and transmission vectors.

\begin{tabular}{|c|c|c|c|c|c|c|c|c|}
\hline A.A & Codons & E gene & M gene & $\mathrm{N}$ gene & S gene & SARS-Cov-2 & Human & Bat \\
\hline \multirow[t]{2}{*}{ Phe } & UUU & 0.8 & 0.91 & 0.48 & 1.53 & 1.33 & 0.97 & 1.31 \\
\hline & UUC & 1.20 & 1.09 & 1.52 & 0.47 & 0.67 & 1.03 & 0.69 \\
\hline \multirow[t]{6}{*}{ Leu } & UUA & 0.43 & 0.69 & 0.46 & 1.56 & 1.40 & 0.5 & 1.76 \\
\hline & UUG & 0.86 & 0.69 & 1.99 & 1.12 & 1.30 & 0.85 & 0.64 \\
\hline & CUU & 2.99 & 2.06 & 1.77 & 2.00 & 1.19 & 0.81 & 0.76 \\
\hline & CUC & 0.00 & 1.03 & 0.44 & 0.67 & 0.46 & 1.07 & 0.70 \\
\hline & CUA & 0.86 & 0.86 & 0.66 & 0.50 & 0.88 & 0.46 & 1.51 \\
\hline & CUG & 0.86 & 0.69 & 0.66 & 0.17 & 0.77 & 2.33 & 0.63 \\
\hline \multirow[t]{3}{*}{ Ile } & AUU & 1.00 & 1.65 & 1.93 & 1.74 & 1.46 & 1.13 & 1.29 \\
\hline & AUC & 1.00 & 0.90 & 0.86 & 0.55 & 0.64 & 1.37 & 0.69 \\
\hline & AUA & 1.00 & 0.45 & 0.21 & 0.71 & 0.90 & 0.5 & 1.02 \\
\hline \multirow[t]{4}{*}{ Val } & GUU & 2.15 & 1.00 & 1.00 & 1.98 & 1.45 & 0.79 & 0.91 \\
\hline & GUC & 0.31 & 0.00 & 1.50 & 0.87 & 0.55 & 0.90 & 0.85 \\
\hline & GUA & 0.92 & 2.00 & 0.50 & 0.62 & 0.93 & 0.52 & 1.78 \\
\hline & GUG & 0.62 & 1.00 & 1.00 & 0.54 & 1.06 & 1.79 & 0.46 \\
\hline \multirow[t]{6}{*}{ Ser } & UCU & 3.00 & 0.80 & 1.30 & 2.24 & 1.50 & 1.15 & 1.33 \\
\hline & UCC & 0.00 & 1.20 & 0.49 & 0.73 & 0.55 & 1.17 & 1.33 \\
\hline & UCA & 0.75 & 1.20 & 1.45 & 1.58 & 1.48 & 0.93 & 1.93 \\
\hline & UCG & 0.75 & 0.40 & 0.32 & 0.12 & 0.30 & 0.36 & 0.33 \\
\hline & AGU & 0.75 & 1.60 & 1.46 & 1.03 & 1.57 & 0.98 & 0.93 \\
\hline & AGC & 0.75 & 0.80 & 0.97 & 0.30 & 0.51 & 1.42 & 1.23 \\
\hline \multirow[t]{4}{*}{ Pro } & $\mathrm{CCU}$ & 4.00 & 0.80 & 1.14 & 2.00 & 1.60 & 1.20 & 1.40 \\
\hline & $\mathrm{CCC}$ & 0.00 & 0.00 & 1.00 & 0.28 & 0.32 & 1.22 & 0.44 \\
\hline & CCA & 0.00 & 2.40 & 1.57 & 1.72 & 1.37 & 1.14 & 1.23 \\
\hline & CCG & 0.00 & 0.80 & 0.29 & 0.00 & 0.73 & 0.45 & 1.12 \\
\hline \multirow[t]{4}{*}{ Thr } & ACU & 1.00 & 1.54 & 2.00 & 1.81 & 1.59 & 1.03 & 1.32 \\
\hline & ACC & 0.00 & 0.92 & 0.75 & 0.41 & 0.31 & 1.32 & 0.32 \\
\hline & ACA & 2.00 & 0.92 & 1.00 & 1.65 & 1.82 & 1.19 & 0.94 \\
\hline & ACG & 1.00 & 0.62 & 0.25 & 0.12 & 0.63 & 0.46 & 1.28 \\
\hline \multirow[t]{4}{*}{ Ala } & GCU & 1.00 & 2.51 & 2.06 & 2.13 & 1.26 & 1.08 & 1.66 \\
\hline & GCC & 1.00 & 0.43 & 0.76 & 0.41 & 0.29 & 1.51 & 0.12 \\
\hline & GCA & 0.00 & 0.84 & 0.86 & 1.37 & 1.03 & 0.95 & 1.31 \\
\hline & GCG & 2.00 & 0.21 & 0.32 & 0.10 & 0.97 & 0.46 & 0.69 \\
\hline \multirow[t]{2}{*}{ Tyr } & UAU & 0.00 & 0.89 & 0.36 & 1.48 & 1.22 & 0.93 & 1.08 \\
\hline & UAC & 2.00 & 1.11 & 1.64 & 0.52 & 0.72 & 1.07 & 0.82 \\
\hline \multirow[t]{2}{*}{$\mathrm{His}$} & CAU & 2.00 & 1.60 & 1.50 & 1.53 & 0.76 & 0.85 & 0.81 \\
\hline & CAC & 0.00 & 0.40 & 0.50 & 0.47 & 1.13 & 1.15 & 1.05 \\
\hline \multirow[t]{2}{*}{ Gln } & CAA & 0.00 & 1.00 & 1.54 & 1.48 & 0.87 & 0.49 & 0.95 \\
\hline & CAG & 0.00 & 1.00 & 0.46 & 0.52 & 1.23 & 1.51 & 1.52 \\
\hline
\end{tabular}




\begin{tabular}{|c|c|c|c|c|c|c|c|c|}
\hline A.A & Codons & E gene & M gene & $\mathrm{N}$ gene & S gene & SARS-Cov-2 & Human & Bat \\
\hline \multirow[t]{2}{*}{ Asn } & AAU & 1.60 & 0.73 & 1.45 & 1.23 & 0.77 & 0.98 & 0.48 \\
\hline & AAC & 0.40 & 1.27 & 0.55 & 0.77 & 1.14 & 1.02 & 0.95 \\
\hline \multirow[t]{2}{*}{ Lys } & AAA & 2.00 & 1.14 & 1.35 & 1.25 & 0.86 & 0.88 & 1.05 \\
\hline & AAG & 0.00 & 0.86 & 0.65 & 0.75 & 1.31 & 1.12 & 1.14 \\
\hline \multirow[t]{2}{*}{ Asp } & GAU & 2.00 & 0.33 & 1.17 & 1.39 & 0.69 & 0.99 & 0.86 \\
\hline & GAC & 0.00 & 1.67 & 0.83 & 0.61 & 1.23 & 1.01 & 1.00 \\
\hline \multirow[t]{2}{*}{ Glu } & GAA & 1.00 & 1.71 & 1.33 & 1.42 & 0.77 & 0.85 & 1.00 \\
\hline & GAG & 1.00 & 0.29 & 0.67 & 0.58 & 1.06 & 1.15 & 1.10 \\
\hline \multirow[t]{2}{*}{ Cys } & UGU & 0.67 & 2.00 & 0.00 & 1.40 & 1.00 & 0.95 & 1.00 \\
\hline & UGC & 1.33 & 0.00 & 0.00 & 0.60 & 0.77 & 1.05 & 0.17 \\
\hline \multirow[t]{6}{*}{ Arg } & CGU & 2.00 & 2.14 & 1.24 & 1.28 & 0.41 & 0.54 & 2.23 \\
\hline & CGC & 0.00 & 0.86 & 1.03 & 0.14 & 0.33 & 1.11 & 0.70 \\
\hline & CGA & 2.00 & 0.43 & 1.03 & 0.02 & 1.37 & 0.76 & 0.49 \\
\hline & CGG & 0.00 & 0.00 & 0.41 & 0.28 & 0.79 & 1.31 & 0.58 \\
\hline & AGA & 2.00 & 1.29 & 2.07 & 2.85 & 2.63 & 1.18 & 1.39 \\
\hline & AGG & 0.00 & 1.29 & 0.21 & 1.43 & 1.42 & 1.10 & 0.82 \\
\hline \multirow[t]{4}{*}{ Gly } & GGU & 4.00 & 1.43 & 0.93 & 2.29 & 1.71 & 0.71 & 0.75 \\
\hline & GGC & 0.00 & 0.86 & 1.49 & 0.73 & 0.81 & 1.35 & 0.96 \\
\hline & GGA & 0.00 & 1.71 & 1.21 & 0.83 & 1.01 & 1.01 & 1.49 \\
\hline & GGG & 0.00 & 0.00 & 0.37 & 0.15 & 0.46 & 0.93 & 0.80 \\
\hline
\end{tabular}

\section{Measuring the similarity influences between the overall codon usage of SARS-Cov-2 and that of hosts}

Spearman's correlational distance analysis was used to further estimate similarity of codon usage patterns and to investigate how the overall codon usage patterns of hosts and SARS-Cov-2 participated in evolutionary process. This analysis was performed to determine the similarities of general codon usage patterns between SARS-Cov-2 and hosts. Such RSCU-dependent analysis was applied routinely for the viral hosts, and remain limited to codon usage patterns and similarities [28-31]. Here, we performed this method through the hierarchical clustering analysis of virus and hosts in this study, and estimated their overall codon usage similarities. This optimized method was performed to present a clear sight of codon usage patterns. Two main groups were noted in this analysis. It was shown that one cluster included the virus and the vector (bat) and the other cluster only included the host (human) (Fig. 2). The statistical tests for the distances of RSCU values (each of which was compared with a synonymous shuffling null model) indicated that a significant signature of codon usage patterns existed for vector and SARS-Cov-2 $(P<0.01)$ compared with human and SARS-Cov-2 $(P>0.05)$. This suggested that possible viral transmission in humans may depend on the vector (bat).

\section{Codon usage adaptation in SARS-Cov-2}

Codon adaptation index (CAI) analysis was performed to investigate the relationship between the codon usage patterns and the expression levels of SARSCov-2 coding sequences, which reflected the adaptation of virus to their host cellular machinery. The CAI values are ranged from 0 to 1 , and higher CAI values are considered as higher levels of codon usage bias [32]. The CAl values were obtained for each gene of SARS-Cov- 2 in relation to human and bat, respectively (Fig. 2 and Table S1). In the SARS-Cov- 2 isolates of E genes, the mean CAI value was noted in relation to human $(0.617 \pm 0.001)$ and bat $(0.602 \pm 0.001)$. In the $\mathrm{M}$ genes, the mean CAI value was noted in relation to human $(0.674 \pm 0.001)$ and bat $(0.670 \pm 0.001)$. In the $\mathrm{N}$ genes, the mean CAI value was noted in relation to human $(0.731 \pm 0.001)$ and bat $(0.710 \pm 0.001)$. In the $S$ genes, the mean CAl value was noted in relation to human $(0.710 \pm 0.001)$ and bat $(0.755 \pm 0.001)$. The Student's t-test was applied to estimate the significant differences in this study, and it suggested that there were significant differences in the CAI values (Fig. 3 and Table S1). 


\section{Evolutionary rates of various genes in SARS-Cov-2}

To investigate why the CAI value is not coincident between S genes and the other three genes in relation to human and bat, we estimated the evolutionary rates of SARS-Cov-2 strains whose collection date was known, by the Bayesian coalescent approach according to the sequences of various protein-coding genes. Using the best-fit model, Bayesian estimated the mean substitution rates for these genes were between $2.35 \times 10^{-4}$ and $4.21 \times 10^{-3}$ substitutions per site/year (Table 3). Among the structural proteins-encoding genes, the E gene had the fastest evolutionary rate $\left(4.21 \times 10^{-3}\right)$ and a $95 \%$ highest probability density (HPD) of between $5.40 \times 10^{-8}$ and $1.3 \times 10^{-2}$. The S gene evolved at the slowest rate of $2.35 \times 10^{-4}$ with the $95 \%$ HPD of between $1.29 \times 10^{-8}$ and $7.21 \times 10^{-4}$

Table 3

Bayesian estimates of evolutionary rate of specific gene segments of SARS-Cov-2.

\begin{tabular}{|lll|}
\hline Gene & $\begin{array}{l}\text { Evolutionary rate (nt substitutions } \\
\text { per site per year) }\end{array}$ & $95 \% \mathrm{HPD}$ \\
\hline $\mathrm{E}$ & $4.21 \times 10^{-3}$ & $5.40 \times 10^{-8} \sim 1.3 \times 10^{-2}$ \\
\hline $\mathrm{M}$ & $1.45 \times 10^{-3}$ & $1.11 \times 10^{-7} \sim 4.41 \times 10^{-3}$ \\
\hline $\mathrm{N}$ & $7.96 \times 10^{-4}$ & $1.57 \times 10^{-7} \sim 2.36 \times 10^{-3}$ \\
\hline $\mathrm{S}$ & $2.35 \times 10^{-4}$ & $1.29 \times 10^{-8} \sim 7.21 \times 10^{-4}$ \\
\hline HPD, highest probability density. \\
\hline
\end{tabular}

\section{Discussion}

In the present study, an evolutionary analysis was performed using 41 whole genome sequences of SARS-Cov-2 obtained from different geographic locations. Our results indicated that the SARS-Cov-2 occurring in various regions mainly formed two groups. Apparently, the SARS-Cov-2 has spread to many countries/regions during 2019-2020, and led to a severe global outbreak [33]. Besides, the phylogenetic tree also indicate that the geographical locations play an important role in SARS-Cov-2 evolution, and such findings may help to trace the viral root of emerging strains in the future. In addition, current results also suggest that some infected countries have more than one genetic lineages.

This survey of the SARS-Cov-2 whole genomes suggests a preference for A and U nucleotide over $\mathrm{G}$ and $\mathrm{C}$, indicating this preference influences the codon usage patterns for the viral translation process. This result is similar to our previous study on Crimean-Congo hemorrhagic fever virus (CCHFV), which is also enriched with $A / U$ nucleotide [17]. However, the biological senses of this phenomenon are still unclear, making it crucial to investigate the causes for the significantly increased A/U nucleotide content in the viral genomes [34]. Some previous reports revealed that the amino acids content was also an important factor determining the nucleotide composition at the 1 st and 2 nd codon locations of viral genomes, while the protein alteration was driven by functional selection. Meanwhile, $69 \%$ of the variation at the 3 rd codon locations always implied synonymous or silent mutations, without the influences of functional selection [34].

RSCU analysis can provide some insights to the influence of natural hosts on SARS-Cov-2 although it may require further validation with experimental researches in animal models. Earlier reports indicated that the codon usage patterns of Ebola virus (EBOV) were not similar with its hosts [35, 36]. Our findings are consistent with the previous studies suggesting that $\mathrm{A} / \mathrm{U}$-ended codons are higher enriched in viral genomes than that in the host genomes [37, 38]. Additionally, some earlier researches also suggested that the identical contents of codon usage patterns between virus and their hosts may improve the translation efficiency of the amino acids, while the opposite contents of codon usage patterns may ensure the exact folding of viral proteins [14, 36, 39, 40]. These findings also indicated that the similar codon usage patterns between SARS-Cov-2 and their hosts could improve the ability of viral genome to participate in the translational process. Particularly, the codon usage patterns of SARS-Cov-2 genomes could be largely impacted by the selection pressure of their common hosts, which may promote the adaptation to the cellular environment of their hosts and efficient replication [29, 41]. However, the effect of selection pressure from hosts (human) on building SARS-Cov-2 codon usage patterns is not similar with the vector (bat). Previous reports on EBOV, CCHFV and Flaviviridae virus reflected the codon usage patterns are different within their hosts and vectors [35, 36, 42]. Based on RSCU values, Spearman's correlational distance analysis was also performed to estimate the general codon usage similarities between SARS-Cov-2 and hosts. That makes it clear that possible SARS-Cov-2 transmission in humans is based on its vector (bat). Models of the infection of animals have indicated the substantial constraints on the evolution of arbovirus [43-46]. Consistent with the earlier reports, our results have clearly showed the correlation of overall SARS-Cov-2 codon usage patterns with bat and not with human. According to this finding, we demonstrated that translational selection pressure plays an important role in shaping the codon usage patterns of SARS-Cov-2.

Interestingly, the codon usage patterns of different coding sequences were different, even within a single isolate at the same time. The codon usage patterns of $\mathrm{S}$ genes and $\mathrm{N}$ genes were closer to that of humans, while $\mathrm{E}$ genes and $\mathrm{M}$ genes were closer to that of bats (Table 2 and Fig. S2). This suggested that the evolution of codon usage patterns of SARS-Cov-2 individual coding sequences is possibly related to the function of different genes in viral pathogenesis. To 
further confirm the effect of natural selection, the CAI analysis was performed. CAI was frequently employed to measure the gene expression and the adaptation of SARS-Cov-2 genes to their hosts, which indicated the effect of natural selection. It would suggest that the highly expressed genes reflected a strong bias for specific codons than genes that were less frequently expressed. Therefore, if the CAl value was high, the codon usage bias would be extremely high and the effect of natural selection was prevalent, and vice versa [47]. Based on the CAI values for the SARS-Cov-2 coding sequences, different levels of adaptation of SARS-Cov-2 host and vector were observed. In our results, the greatest adaptation of SARS-Cov-2 S genes were to bat, closely followed by human, indicating that the replication of $S$ genes may be more efficient in the vector cells than in the host cells. However, CAI values for the other three genes ( $\mathrm{E}, \mathrm{M}$ and $\mathrm{N}$ ) tended to be higher for human, which may be attributable to the possibly higher efficiency of protein synthesis within its host.

To further investigate the inconsistent adaptation of different genes, we deduced the evolutionary rates of SARS-Cov-2 strains. In most cases, it is less significant to consider the collection date than the location of isolated sequences. However, as for fasting-evolving organisms like RNA viruses, isolation changes in the date could be used to evaluate the time since virus last shared one common ancestor. So we required the collection date of SARS-Cov- 2 to assume the constant evolutionary rates of divergence between sequences. Additionally, according to the assumption of substitution rate constancy, the differences of isolation dates could provide information about the rates of molecular evolution. In other words, the quantity of evolutionary rate has accumulated since the collection date [48]. A Bayesian coalescent approach suggested the mean substitution rates were between $2.35 \times 10^{-4}$ and $4.21 \times 10^{-3}$ in different genes, which was comparable with the reports for hepatitis A and B viruses and Newcastle disease virus [49-51]. It has suggested that the lowest substitution rate of the SARS-Cov-2 S genes may contribute to its more important function in viral synthesis and replication, which may be subjected to lesser natural selection pressure and suffered fewer substitution.

\section{Conclusion}

In conclusion, this study indicated that the codon usage patterns of SARS-Cov-2 were mainly shaped by the translation selection. Importantly, there were similarities of codon usage patterns between SARS-Cov-2 and its natural hosts. It also demonstrated that different genes have different adaptation to their hosts. And we further suggested that SARS-Cov-2 isolates were evolving at a rapid substitution rate under their translation selection pressure of their hosts. The present study will be required to build SARS-Cov-2 adaptation in different hosts that will contribute to the understanding and control of SARS-Cov-2 infection and transmission.

\section{Methods}

\section{Data collection}

The newly sequenced 41 SARS-Cov-2 complete genomes have been downloaded

from the GenBank database (http://www.ncbi.nIm.nih.gov/genbank/). The comprehensive information of SARS-Cov-2 strains were provided in Supplementary Table S1, including the accession number, collection date, viral host and the geographic origin of isolation. Out of them, different datasets were extracted from the whole genome sequences, containing the $E, M, N$ and $S$ structural genes, and used in the further analysis. The sequences were aligned using the local software MAFFT v7.450 [52], and manually adjusted using BioEdit v7.2.5 [53].

\section{Phylogenetic analysis of SARS-Cov-2}

The phylogenetic tree was reconstructed using maximum-likelihood method in PAML v4.9 and was estimated by the bootstrap analysis with 1000 replicates. The tree was designed by the online software named the Interactive Tree Of Life v2 [54]. A total of 41 SARS-Cov-2 strains were used in our research.

\section{Nucleotide contents analysis}

The nucleotide content analysis of 41 SARS-Cov-2 whole genomes were calculated using CodonW software. The total nucleotide content of A, U, G and C, the nucleotide content at the 3rd location (A3, U3, G3 and C3), and GC nucleotide content at the 1st (GC1), 2nd (GC2) and 3rd (GC3) locations were measured individually. Additionally, the average frequency of GC at $1 \mathrm{st}$ and 2 nd positions and the whole AU/GC compositions were also calculated. Nonsynonymous codons (UGG and AUG) and termination codons (UAA, UAG and UGA) were abandoned from this study.

\section{Synonymous Codon Usage Analysis}

To evaluate the relative synonymous codon usage (RSCU) bias of SARS-Cov- 2 and the potential hosts, coding sequences of SARS-Cov- 2 whole genome (408321 codons) and Vespertilio murinus genes (29616 codons) were calculated in Codon W1.4.2 [15, 55, 56]. The RSCU of Homo sapiens genes (40662582 codons) was obtained from the Codon Usage Database (http://www.kazusa.or.jp/codon/). The RSCU values of each structural gene (E, M, N and S) were also considered in this study. The RSCU values are the ratio between one observed codon usage frequency in a gene sequence and its expected usage frequency of the corresponding synonymous codon family, provided that all codons for specific amino acids are used equally. The codons with RSCU > 1.0 suggest positive codon usage bias, which are defined as 'abundant' codons. While those with RSCU $<1.0$ suggest negative codon usage bias, which are named as 'less abundant' codons. And there is equally or randomly used of synonymous codons for the corresponding amino acids when the RSCU is 1.0 [57]. The RSCU > 1.6 and $<0.6$ are treated as 'overrepresented' codons and 'underrepresented' codons, respectively [29]. Besides, a heat map of RSCU values was performed by Heatmap Illustrator v1.0 software [58]. The SARS-Cov-2 and its potential hosts were clustered by the Euclidean distance method. 


\section{Identifying the similarity effect of codon usage bias}

In this study, the RSCU values of all synonymous codons were used to discern the similarity influence among these organisms. Except for Met (AUG), Trp (UGG) and three stop codons (UAA, UAG, UGA), all codons were arranged in a matrix containing $\mathrm{N} \times \mathrm{M}$ dimensions. Here, $\mathrm{N}$ represents the number of organism species and $\mathrm{M}$ represents the number of degenerated synonymous codons. Hierarchical clustering for this matrix was performed by Bioconductor with Ward's method on the basis of Spearman's correlational distance for RSCU values [59]. The resulting dendrogram was drown with ggplot2 in R program [60]. Additionally, the observed probability was performed as the P-value to display significance.

\section{Codon adaptation index}

As a quantitative measure, the codon adaptation index (CAI) was performed to estimate the gene expression level on the basis of its coding sequences, and ranged from 0 to 1 . The higher frequent codons suggested the higher relative adaptation to their hosts, and genes with higher CAI values were considered to be fitted over those with lower CAI values [61]. CAI analysis of the SARS-Cov-2 coding sequences was employed with CAlcal server, which implemented an improved method of CAI calculation [47]. The codon usage patterns of Vespertilio murinus and Homo sapiens were used as references. Except for the three termination codons, nonsynonymous codons (UGG and AUG) were also excluded in our study.

\section{Evolution substitution rates}

We analyzed 41 representative whole genome sequences of SARS-Cov- 2 isolates during 2019 to 2020 with the MCMC program in BEAST v 2.4 .8 software to measure the evolutionary rate of different genes. Under the model that assumed a constant substitution rate, this program provided a maximum-likelihood method to estimate the rate. The jModel Test software $v$ 2.0.1 was performed to choose the best-fitted model based on the Akaike information criterion (AIC) [62]. For model comparison, the Bayes factor could estimate each model test and yield the best results with marginal likelihood estimated on the basis of Newton \& Raftery method [63]. As implemented in BEAST package, the best-fitted model was GTR (general time reversible) $+\lceil 4$ (gamma distribute rate variation) + I (proportion of invariant sites) + Lognormal relaxed uncorrelated clock and coalescent constant population models. The MCMC analysis was implemented with 300 million generations and sampled every 2000 generations with $10 \%$ burn-in. The results were analyzed by Tracer $v 2.4 .8$ program. Statistical uncertainty was indicated in the $95 \%$ HPD values.

\section{Declarations}

\section{Ethics approval and consent to participate}

Not applicable.

\section{Consent for publication}

Not applicable.

\section{Availability of data and materials}

The datasets generated and analyzed during the current study are available in the GenBank repository, [http://www.ncbi.nlm.nih.gov/genbank/].

\section{Competing interests}

The authors declare that they have no competing interests.

\section{Funding}

This work was supported by Key Industrial Innovation Chains of Shaanxi province (2020ZDLNY02-06) and Qinghai Province Major R\&D and Transformation Project (2018-NK-125).

\section{Author contributions}

DKC and WTM conceived and designed experiments; XTY and YFX performed all experiments. XTY, XG and SLN collected and analyzed the data. XTY, SUR and CXZ drafted the manuscript. All authors read and approved the final manuscript.

\section{Acknowledgements}

Not applicable. 


\section{References}

1. Madurai Elavarasan R, Pugazhendhi R. Restructured society and environment: A review on potential technological strategies to control the COVID-19 pandemic. Sci Total Environ 2020:138858.

2. Chakraborty I, Maity P. COVID-19 outbreak: Migration, effects on society, global environment and prevention. Sci Total Environ. 2020;728:138882.

3. Wang WTJ, Wei F. Updated understanding of the outbreak of 2019 novel coronavirus (2019-nCoV) in Wuhan, China. J Med Virol 2020 Apr, $92(4)$ :441-447.

4. Ciotti M, Angeletti S, Minieri M, Giovannetti M, Benvenuto D, Pascarella S, Sagnelli C, Bianchi M, Bernardini S, Ciccozzi M. COVID-19 Outbreak: An Overview. Chemotherapy. 2019;64(5-6):215-23.

5. Chen YLQ, Guo D. Emerging coronaviruses: Genome structure, replication, and pathogenesis. J Med Virol 2020 Apr, 92(4):418-423.

6. Kan BWM, Jing H, Xu H, Jiang X, Yan M, Liang W, Zheng H, Wan K, Liu Q, Cui B, Xu Y, Zhang E, Wang H, Ye J, Li G, Li M, Cui Z, Qi X, Chen K, Du L, Gao K, Zhao YT, Zou XZ, Feng YJ, Gao YF, Hai R, Yu D, Guan Y, Xu J. Molecular evolution analysis and geographic investigation of severe acute respiratory syndrome coronavirus-like virus in palm civets at an animal market and on farms. J Virol 2005 Sep, 79(18):11892-11900.

7. Li WSZ, Yu M, Ren W, Smith C, Epstein JH, Wang H, Crameri G, Hu Z, Zhang H, Zhang J, McEachern J, Field H, Daszak P, Eaton BT, Zhang S, Wang LF. Bats are natural reservoirs of SARS-like coronaviruses. Science 2005 Oct 28, 310(5748):676-679.

8. Wei Ji WW, Xiaofang Zhao J, Zai X, Li. Homologous recombination within the spike glycoprotein of the newly identified coronavirus may boost crossspecies transmission from snake to human. J Med Virol 2020, [Epub ahead of print, 22 Jan 2020].

9. Li GFY, Lai Y, Han T, Li Z, Zhou P, Pan P, Wang W, Hu D, Liu X, Zhang Q, Wu J. Coronavirus infections and immune responses. J Med Virol 2020 Apr, 92(4):424-432.

10. Butt AM, Nasrullah I, Qamar R, Tong Y. Evolution of codon usage in Zika virus genomes is host and vector specific. Emerg Microbes Infect. 2016;5(10):e107.

11. Qin H, Wu WB, Comeron JM, Kreitman M, Li WH. Intragenic spatial patterns of codon usage bias in prokaryotic and eukaryotic genomes. Genetics. 2004;168(4):2245-60.

12. Adams MJ, Antoniw JF. Codon usage bias amongst plant viruses. Arch Virol. 2004;149(1):113-35.

13. Shackelton LA, Parrish CR, Holmes EC. Evolutionary basis of codon usage and nucleotide composition bias in vertebrate DNA viruses. J Mol Evol. 2006;62(5):551-63.

14. Hu C, Chen J, Ye L, Chen R, Zhang L, Xue X. Codon usage bias in human cytomegalovirus and its biological implication. Gene. 2014;545(1):5-14.

15. Karniychuk UU. Analysis of the synonymous codon usage bias in recently emerged enterovirus D68 strains. Virus Res. 2016;223:73-9.

16. Kattoor JJMY, Sasidharan A, Rajan VM, Dhama K, Ghosh S, Bányai K, Kobayashi N, Singh RK. Analysis of codon usage pattern evolution in avian rotaviruses and their preferred host. Infect Genet Evol 2015 Aug, 34:17-25.

17. Rahman SU, Yao X, Li X, Chen D, Tao S. Analysis of codon usage bias of Crimean-Congo hemorrhagic fever virus and its adaptation to hosts. Infect Genet Evol. 2018;58:1-16.

18. Kandeel M, Ibrahim A, Fayez M, Al-Nazawi M. From SARS and MERS CoVs to SARS-CoV-2: Moving toward more biased codon usage in viral structural and nonstructural genes. J Med Virol. 2020;92(6):660-6.

19. Tort FL, Castells M, Cristina J. A comprehensive analysis of genome composition and codon usage patterns of emerging coronaviruses. Virus Res. 2020;283:197976.

20. Dilucca M, Forcelloni S, Georgakilas AG, Giansanti A, Pavlopoulou A. Codon Usage and Phenotypic Divergences of SARS-CoV-2 Genes. Viruses 2020, 12(5).

21. Gu H, Chu DKW, Peiris M, Poon LLM. Multivariate analyses of codon usage of SARS-CoV-2 and other betacoronaviruses. Virus Evol. 2020;6(1):veaa032.

22. Goñi NIA, Comas V, Soñora M, Moreno P, Moratorio G, Musto H, Cristina J. Pandemic influenza A virus codon usage revisited: biases, adaptation and implications for vaccine strain development. Virol J 2012 Nov 8, 9:263.

23. Wong EH, Smith DK, Rabadan R, Peiris M, Poon LL. Codon usage bias and the evolution of influenza A viruses. Codon Usage Biases of Influenza Virus. BMC Evol Biol. 2010;10:253.

24. Chen SLLW, Hottes AK, Shapiro L, McAdams HH. Codon usage between genomes is constrained by genome-wide mutational processes. Proc Natl Acad Sci U S A. 2004;101(10):3480-5.

25. Galtier N, Roux C, Rousselle M, Romiguier J, Figuet E, Glemin S, Bierne N, Duret L. Codon Usage Bias in Animals: Disentangling the Effects of Natural Selection, Effective Population Size, and GC-Biased Gene Conversion. Mol Biol Evol. 2018;35(5):1092-103.

26. Wang H, Liu S, Zhang B, Wei W. Analysis of Synonymous Codon Usage Bias of Zika Virus and Its Adaption to the Hosts. PLoS One. 2016;11(11):e0166260.

27. Bahir IFM, Prat Y, Linial M. Viral adaptation to host: a proteome-based analysis of codon usage and amino acid preferences. Mol Syst Biol. $2009 ; 5: 311$.

28. Ma MR, Ha XQ, Ling H, Wang ML, Zhang FX, Zhang SD, Li G, Yan W. The characteristics of the synonymous codon usage in hepatitis B virus and the effects of host on the virus in codon usage pattern. Virol J. 2011;8:544.

29. Wong EHSD, Rabadan R, Peiris M, Poon LL. Codon usage bias and the evolution of influenza A viruses. Codon Usage Biases of Influenza Virus. BMC Evol Biol 2010 Aug 19, 10:253.

30. Zhou JH, Zhang J, Sun DJ, Ma Q, Chen HT, Ma LN, Ding YZ, Liu YS. The distribution of synonymous codon choice in the translation initiation region of dengue virus. PLoS One. 2013;8(10):e77239.

Page $11 / 15$ 
31. Zhou JH, Gao ZL, Zhang J, Chen HT, Pejsak Z, Ma LN, Ding YZ, Liu YS. Comparative [corrected] codon usage between the three main viruses in pestivirus genus and their natural susceptible livestock. Virus Genes. 2012;44(3):475-81.

32. Butt AM, Nasrullah I, Tong Y. Genome-wide analysis of codon usage and influencing factors in chikungunya viruses. PLoS One. $2014 ; 9$ (3):e90905.

33. Guo YR, Cao QD, Hong ZS, Tan YY, Chen SD, Jin HJ, Tan KS, Wang DY, Yan Y. The origin, transmission and clinical therapies on coronavirus disease 2019 (COVID-19) outbreak - an update on the status. Mil Med Res. 2020;7(1):11.

34. van Hemert F, Berkhout B. Nucleotide composition of the Zika virus RNA genome and its codon usage. Virol J. 2016;13:95.

35. Schubert AMPC. Evolution of the sequence composition of Flaviviruses. Infect Genet Evol 2010 Jan, 10(1):129-136.

36. Cristina J, Moreno P, Moratorio G, Musto H. Genome-wide analysis of codon usage bias in Ebolavirus. Virus Res. 2015;196:87-93.

37. Rabadan R, Levine AJ, Robins H. Comparison of avian and human influenza A viruses reveals a mutational bias on the viral genomes. J Virol. 2006;80(23):11887-91.

38. Greenbaum BD, Levine AJ, Bhanot G, Rabadan R. Patterns of evolution and host gene mimicry in influenza and other RNA viruses. PLoS Pathog. 2008;4(6):e1000079.

39. Aragones L, Guix S, Ribes E, Bosch A, Pinto RM. Fine-tuning translation kinetics selection as the driving force of codon usage bias in the hepatitis A virus capsid. PLoS Pathog. 2010;6(3):e1000797.

40. Costafreda MI, Perez-Rodriguez FJ, D'Andrea L, Guix S, Ribes E, Bosch A, Pinto RM. Hepatitis A virus adaptation to cellular shutoff is driven by dynamic adjustments of codon usage and results in the selection of populations with altered capsids. J Virol. 2014;88(9):5029-41.

41. Ma YP, Liu ZX, Hao L, Ma JY, Liang ZL, Li YG, Ke H. Analysing codon usage bias of cyprinid herpesvirus 3 and adaptation of this virus to the hosts. J Fish Dis. 2015;38(7):665-73.

42. Ur Rahman S, Mao Y, Tao S. Codon usage bias and evolutionary analyses of Zika virus genomes. Genes Genomics. 2017;39(8):855-66.

43. Das BDM, Dwibedi B, Kar SK, Hazra RK. Molecular investigations of dengue virus during outbreaks in Orissa state, Eastern India from 2010 to 2011 . Infect Genet Evol 2013 Jun, 16:401-410.

44. Dieng HSR, Hassan AA, Salmah MR, Boots M, Satho T, Jaal Z, AbuBakar S. Indoor-breeding of Aedes albopictus in northern peninsular Malaysia and its potential epidemiological implications. PLoS One 2010 Jul 27, 5(7):e11790.

45. Martins VEAC, Kamimura MT, de Carvalho Araújo FM, De Simone SG, Dutra RF, Guedes MI. Occurrence of natural vertical transmission of dengue-2 and dengue-3 viruses in Aedes aegypti and Aedes albopictus in Fortaleza, Ceará, Brazil. PLoS One. 2012;7(7):e41386.

46. Yao HCM, Tang Z. Analysis of Synonymous Codon Usage Bias in Flaviviridae Virus. Biomed Res Int 2019 Jun. 2019;27:5857285.

47. Puigbo P, Bravo IG, Garcia-Vallve S. CAlcal: a combined set of tools to assess codon usage adaptation. Biol Direct. 2008;3:38.

48. Keightley PD E-WA. Estimating the rate of adaptive molecular evolution when the evolutionary divergence between species is small. J Mol Evol 2012 Feb, 74(1-2):61-68.

49. Wang HWX, Zheng HH, Cao JY, Zhou WT, Bi SL. Evolution and genetic characterization of hepatitis A virus isolates in China. Int J Infect Dis 2015 Apr, 33:156-158.

50. Alvarado Mora MVRC, Gomes-Gouvêa MS, Gutierrez MF, Botelho L, Carrilho FJ, Pinho JR. Molecular characterization of the Hepatitis B virus genotypes in Colombia: a Bayesian inference on the genotype F. Infect Genet Evol 2011 Jan, 11(1):103-108.

51. Miller PJKL, Ip HS, Afonso CL. Evolutionary dynamics of Newcastle disease virus. Virology 2009 Aug 15, 391(1):64-72.

52. Katoh KSD. MAFFT multiple sequence alignment software version 7: improvements in performance and usability. Mol Biol Evol 2013 Apr, 30(4):772-780.

53. Hall TA. BioEdit: a user-friendly biological sequence alignment editor and analysis program for Windows 95/98/NT. Nucl Acids Symp Ser. 1999;41:95-8.

54. Letunic IBP. Interactive Tree Of Life v2: online annotation and display of phylogenetic trees made easy. Nucleic Acids Res 2011 Jul, 39 (Web Server issue):W475-478.

55. F W. The 'effective number of codons' used in a gene. Gene 1990 Mar 1, 87(1):23-29.

56. Liu XSZY, Fang YZ, Wang YL. Patterns and influencing factor of synonymous codon usage in porcine circovirus. Virol J 2012 Mar 15, 9:68.

57. Sharp PMLW. An evolutionary perspective on synonymous codon usage in unicellular organisms. J Mol Evol. 1986;24(1-2):28-38.

58. Deng WWY, Liu Z, Cheng H, Xue Y. Heml: a toolkit for illustrating heatmaps. PLoS One 2014 Nov 5, 9(11):e111988.

59. Gentleman RCCV, Bates DM, Bolstad B, Dettling M, Dudoit S, Ellis B, Gautier L, Ge Y, Gentry J, Hornik K, Hothorn T, Huber W, lacus S, Irizarry R, Leisch F, Li C, Maechler M, Rossini AJ, Sawitzki G, Smith C, Smyth G, Tierney L, Yang JY, Zhang J. Bioconductor: open software development for computational biology and bioinformatics. Genome Biol. 2004;5(10):R80.

60. Ito KMD. Application of ggplot2 to Pharmacometric Graphics. CPT Pharmacometrics Syst Pharmacol 2013 Oct 16, 2:e79.

61. Sharp PMLW. The codon Adaptation Index-a measure of directional synonymous codon usage bias, and its potential applications. Nucleic Acids Res 1987 Feb 11, 15(3):1281-1295.

62. D P. jModelTest: phylogenetic model averaging. Mol Biol Evol 2008 Jul, 25(7):1253-1256.

63. Capistrano ESMME, Schmidt AM. Bayesian estimation of the average treatment effect on the treated using inverse weighting. Stat Med 2019 Jun, 15;38(13):2447-2466.

\section{Figures}




Colllected region
$\square$ China_Wuhan
$\square$ China_Yunnan
$\square$ China_Hangzhou
$\square$ China_Shenzhen
$\square$ Taiwan
$\square$ Australia
$\square$ USA
$\square$ Japan
$\square$ South_Korea

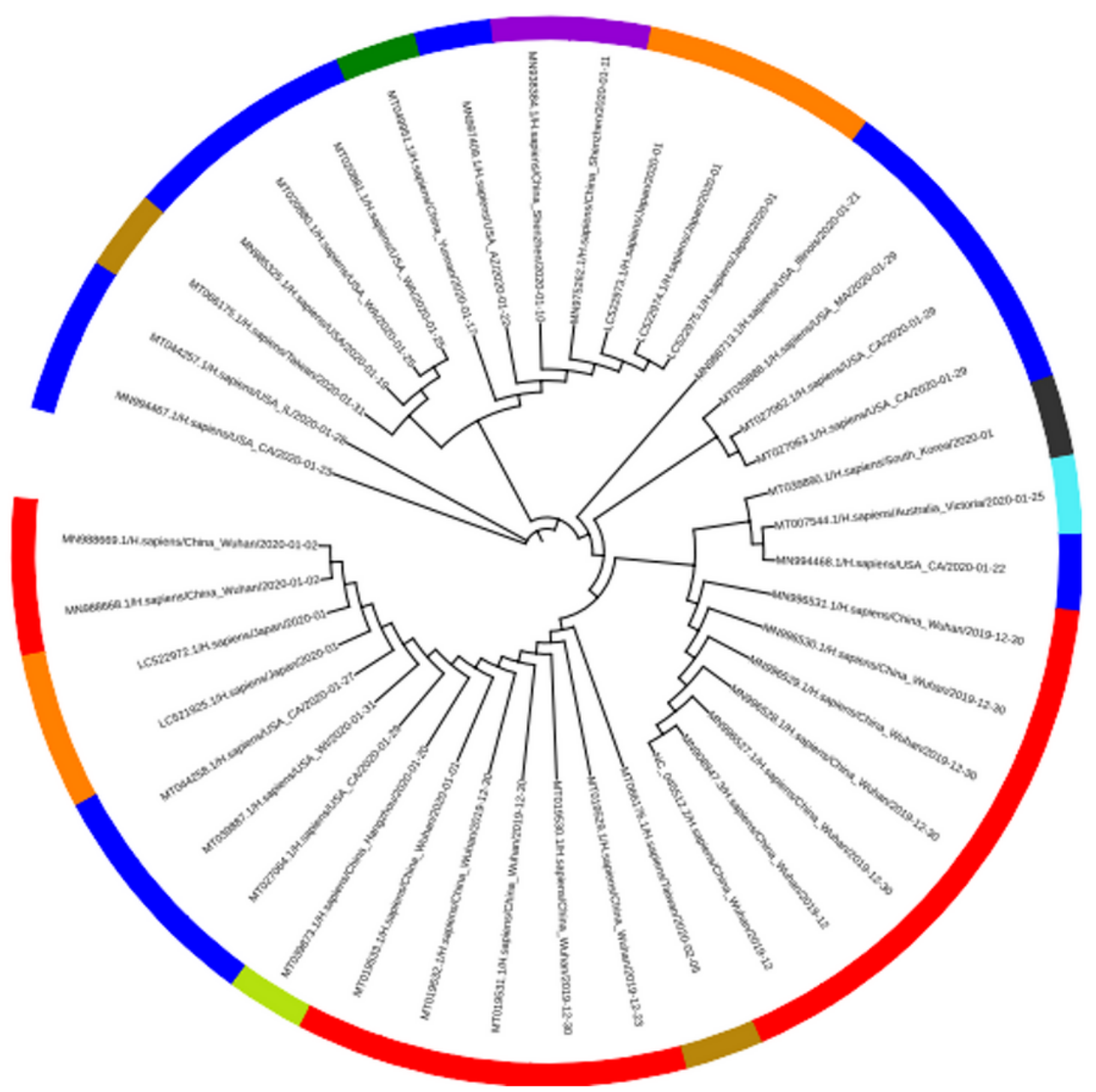

Figure 1

Phylogenetic tree based on the whole genome sequences of 41 SARS-Cov-2 strains. The tree was generated by the maximum likelihood (ML) method using PAML v4.9. The tree was designed by using the online tool "iTOL". 


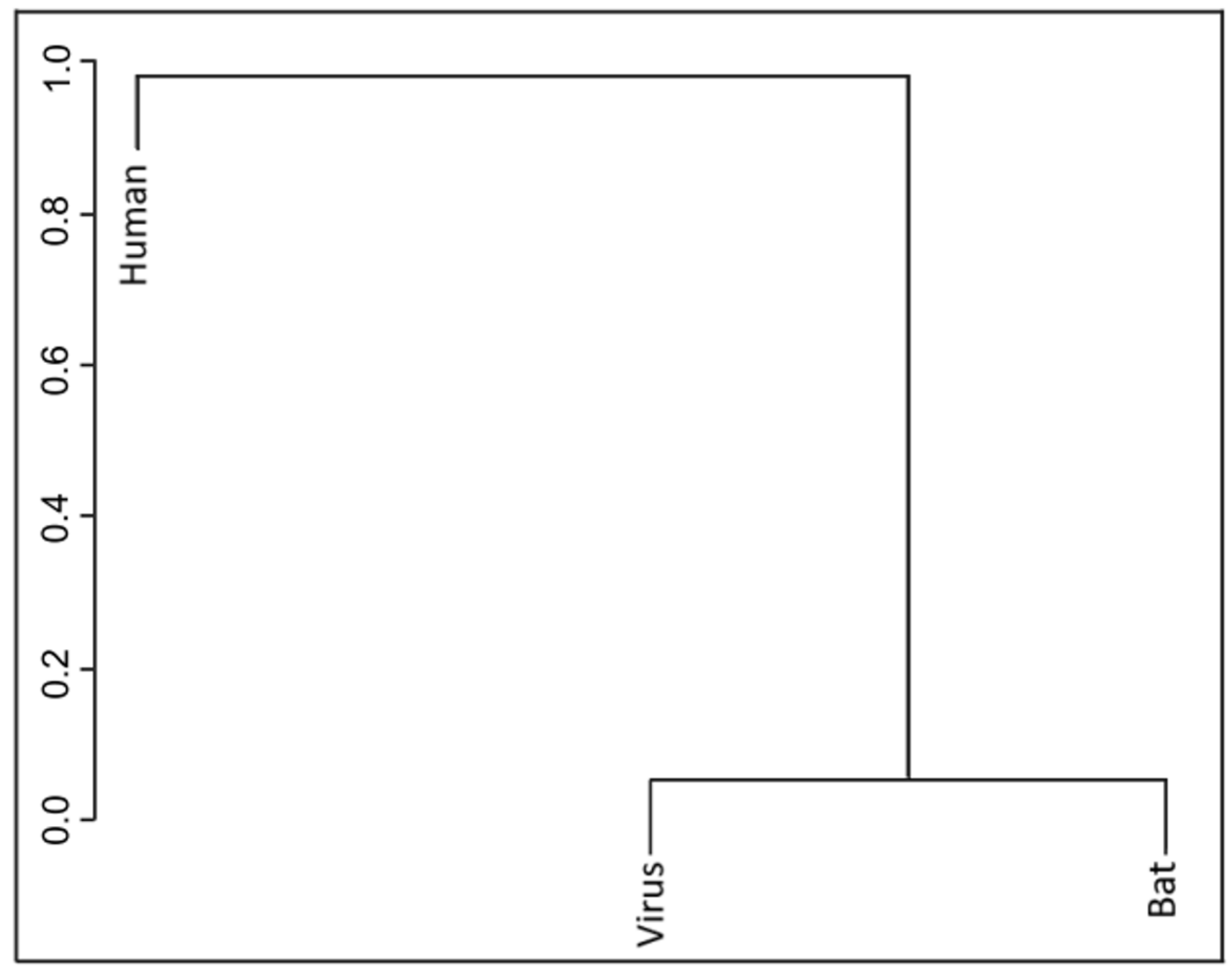

Figure 2

Similarity distance analysis of the codon usage using SARS-Cov-2 and its hosts (Spearman correlational distances $=1-$ SpearmanRho). 


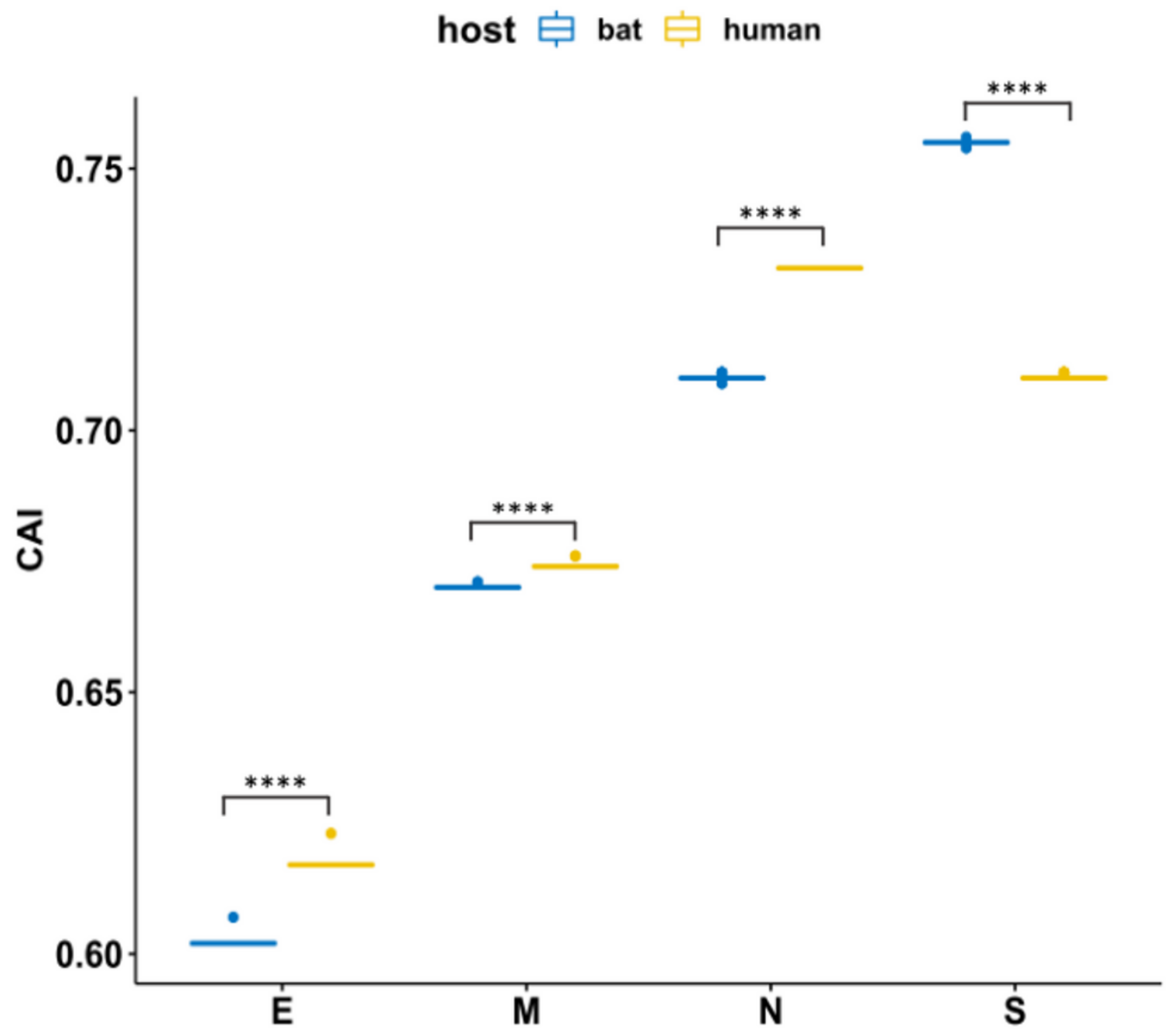

Figure 3

CAI of SARS-Cov-2 coding sequences to its hosts. In the plot, the $\mathrm{x}$-axis represents different genes of SARS-Cov-2. The Y-axis represents the CAI value. Different colors represent different host species: blue- bat, and yellow - human. Different asterisks represent statistical significance ${ }^{\star} \mathrm{p}<0.05,{ }^{* \star} \mathrm{p}<0.01$, ${ }^{\star \star \star} \mathrm{p}$ $<0.001, * \star \star * \mathrm{p}<0.0001)$.

\section{Supplementary Files}

This is a list of supplementary files associated with this preprint. Click to download.

- supplementarytable.docx

- supplementaryfigure.docx 